\title{
Differences in narrative productions of closed head-injured adults
}

\author{
WILLIAM B. WOLFOLK and DONALD FUCCI \\ Ohio University, Athens, Ohio
}

and

\author{
FAY E. DUTKA, LAURA M. HERBERHOLZ, and TINA M. LATORRE \\ Wayne State University, Detroit, Michigan
}

\begin{abstract}
The purpose of this study was to compare the abilities of 9 high-level, closed head-injured (CHI) adult subjects $(M$ age $=31$ years, age range $=20-56$ years) utilizing the narrative tasks of storytelling and story generation. Analysis of the language used under the two conditions was found to be similar to that described in a study by Liles, Coelho, Duffy, and Zalagens (1989), which characterized discourse problems observed in four closed head-injured subjects. Findings appeared to indicate that the performances of the subjects on the two narration tasks demonstrated significant differences in length, complexity, and focus of narrations. The described procedure appeared to be a useful method of characterizing the kinds of language deficits displayed by this population of subjects.
\end{abstract}

Individuals with closed head injuries who recover language skills with high-level functional ability often present problems in clinical assessment (Liles, Coelho, Duffy, \& Zalagens, 1989). These problems arise from a discrepancy in communicative behavior between standardized language assessment tools and various discourse situations. Often, there is no evidence of communicative abnormality on standardized batteries (Liles et al., 1989). However, communicative performance in discourse may be perceived as abnormal by listeners.

Many investigators (Coelho, Liles, \& Duffy, 1987; Mentis \& Prutting, 1987; Wycoff, 1984) have utilized a method proposed by Halliday and Hasan (1976) to examine the discourse of closed head-injured (CHI) subjects. The established model is based on the proposition that speakers create "cohesive texts" by conjoining meaning across sentences, where various linguistic markers are used. These linguistic markers are dependent on such factors as the type of text, text content, and personal style. A cohesive pattern develops from the speaker's choice of linguistic marker categories.

Normal speakers shift their cohesive pattern across different types of discourse (Liles et al., 1989), but the ability of high-level CHI subjects to alter their cohesive pattern is impaired and is dependent on a changing context. While only one type of discourse text (i.e., the story) was examined and compared with that of normal subjects, the extralinguistic context was varied through the tasks of storytelling and story generation.

The present subjects' performances were compared with the sentence production and cohesive patterns of the $\mathrm{CHI}$

Correspondence should be addressed to W. B. Wolfolk, School of Hearing and Speech Sciences, Lindley Hall 201, Ohio University, Athens, OH 45701. and normal subjects in the Liles et al. (1989) study to learn if their performances were consistent with those of other CHI subjects.

\section{METHOD}

\section{Subjects}

The $9 \mathrm{CHI}$ subjects utilized in this study ranged in age from 20 to 56 years, with a mean age of 31 years. They were chosen according to the following criteria: (1) no significant visual acuity or visual perceptual deficits, (2) no significant hearing loss, (3) nonaphasic, (4) no significant motor speech disorder, and (5) Rancho Los Amigos Level V or above.

\section{Procedure}

Stories were elicited from the subjects under two conditions: storytelling and story generation. For the storytelling task, the subjects were presented with a copy of a sequenced story on four sheets of standardsized white paper with line drawings and without graphic elaboration. The story had 15 frames depicting a young boy's walk through a forest. After viewing the pictures, the subjects were given the following instructions: "Tell me the story." For the story-generation task, the subjects were presented with a copy of Norman Rockwell's painting "The Runaway." The subjects were given the instructions: "Tell me a story about the picture." The picture remained in view of the examiner and the subject until the task was completed.

Each story was audiotaped and later transcribed verbatim. The transcriptions were distributed into $\mathrm{T}$ units (defined as an independent clause plus any dependent clauses associated with the independent clause) prior to analysis (Liles et al., 1989). Sentence production and intersentential cohesion were measured. The total number of $T$ units was calculated for each story and served as the measure of verbal output or productivity. The total number of subordinate clauses per $\mathrm{T}$ unit were calculated for each story. The total number of cohesive ties per $T$ unit and the total number of markers for each category of marker per $\mathrm{T}$ unit were obtained.

\section{RESULTS}

The scores of the CHI subjects were converted to $z$ scores to allow for comparison with the Liles et al. (1989) study. 
Scores within a range of +1.65 to -1.65 were considered to be within average limits.

Data representing the sentence production of the normal subjects of the Liles et al. (1989) study and the CHI subjects of the current study for the telling and generation tasks are presented in Table 1 . It can be seen in Table 1 that all of the subjects in the study exhibited a greater number of $T$ units for the telling task than they did for the generation task. One exception, Subject G, produced an equal number of $T$ units for both tasks. By studying the number of subordinate clauses per $T$ unit, it can be seen that all subjects, with the exception of Subject D, exhibited $z$ scores within average limits for the telling task; however, for the generation task, all subjects exhibited $z$ scores within average limits, with the exception of 3 (Subjects A, B, and E), whose $z$ scores were higher. Looking across the tasks shown in Table 1, it can be seen that 5 subjects (Subjects B, C, E, H, and I) used subordinate clauses more in generation than they did in telling. Two subjects (Subjects D and F) used more subordinate clauses in telling than they did in generation, and 2 subjects (Subjects $A$ and $G$ ) did not use subordinate clauses under either condition.

Data descriptive of the total number of cohesive ties per $\mathrm{T}$ unit produced by the normal subjects of the Liles et al. (1989) study and the CHI subjects of the current study are presented in Tables 2 and 3. In the telling task, the $z$ scores of 5 subjects (Subjects B, E, F, H, and I) were within average limits; the $z$ scores of 4 subjects (Subjects $A, C, D$, and $G$ ) were not within average limits. In the generation task, the $z$ scores of 5 subjects (Subjects B, C, E, H, and I) were within average limits; the $z$ scores of 4 subjects (Subjects A, D, F, and G) were not within average limits. When comparing the tasks of telling and generation displayed in Tables 2 and 3, it can be seen that 5 subjects (Subjects B, C, E, G, and I) produced a higher ratio of cohesive ties in generation than in telling; 4 subjects (Subjects A, D, F, and H) did not.
Data descriptive of the pattern of style of cohesion used by the subjects in this study are also presented in Tables 2 and 3. The $z$ scores representing the reference pattern of style in the telling task for 4 subjects (Subjects B, C, $\mathrm{H}$, and $\mathrm{I}$ ) were within average limits; for 5 subjects (Subjects $A, D, E, F$, and $G$ ), the $z$ scores were not within average limits. The $z$ scores representing the lexical pattern of cohesion were within average limits for all subjects, with one exception (Subject F). The $z$ scores representing conjunctive cohesion for 6 subjects (Subjects C, D, F, G, H, and I) were within average limits; 3 subjects (Subjects A, B, and E) showed $z$ scores that were not within average limits.

In the generation task, the $z$ scores representing the reference pattern of cohesion shows that 5 subjects (Subjects $B, C, E, H$, and I) were within average limits and 4 subjects (Subjects A, D, F, and G) were not within average limits. The $z$ scores representing the lexical pattern of cohesion were within average limits for 6 subjects (Subjects A, D, F, G, H, and I) but were not within average limits for 3 subjects (Subjects B, C, and E). The $z$ scores representing the conjunctive pattern of cohesion were within average limits for 6 subjects (Subjects A, B, E, F, G, and H) but were not for 3 subjects (Subjects C, D, and I).

\section{DISCUSSION}

\begin{abstract}
The results of the present study and the Liles et al. (1989) investigation were similar. The results indicated that the tasks of storytelling and story generation have differential effects on the language used in the narrative discourse (Liles et al., 1989). The effects were demonstrated in narrative length and sentence formulation. All subjects produced longer narratives in telling than they did in generation, with one exception (Subject $G)$, who produced an equal number of $T$ units for each task.

The difference noted between tasks leads to the suggestion that the subjects intended to tell the entire story with a focus on detail, rather than a focus on an event in generation (Liles et al., 1989). This difference may further be interpreted as one of complexity, in that story generation is generally more complex than storytelling. The subjects' overall performances provided support to this interpretation in that their
\end{abstract}

Table 1

Number of T Units and Number of Subordinate Clauses per T Unit for Telling (TEL) and Generation (GEN) Tasks, and $z$ Scores for Each CHI Subject

\begin{tabular}{|c|c|c|c|c|c|c|c|c|}
\hline \multirow[b]{3}{*}{ Subjects } & \multicolumn{4}{|c|}{ T Units } & \multicolumn{4}{|c|}{ Subordinate Clauses per $\mathrm{T}$ Unit } \\
\hline & \multicolumn{2}{|c|}{ TEL } & \multicolumn{2}{|c|}{ GEN } & \multicolumn{2}{|c|}{ TEL } & \multicolumn{2}{|c|}{ GEN } \\
\hline & Number & $z$ Score & Number & $z$ Score & Number & $z$ Score & Number & $z$ Score \\
\hline \multicolumn{9}{|c|}{ Normal:* } \\
\hline$M$ & 19.4 & - & 9.3 & - & 0.11 & - & 0.59 & - \\
\hline$S D$ & 7.7 & - & 3.1 & - & 0.10 & - & 0.34 & - \\
\hline Range & $5-32$ & - & $5-16$ & - & $0-0.14$ & - & $0.8-1.33$ & - \\
\hline \multicolumn{9}{|l|}{ CHI: } \\
\hline $\mathbf{A}$ & 17 & 0.31 & 4 & -1.7 & $\mathbf{0}$ & -1.1 & $\mathbf{0}$ & -1.7 \\
\hline B & 12 & -0.96 & 4 & -1.7 & 0 & -1.1 & 0.25 & -1.0 \\
\hline C & 11 & -1.9 & 5 & -1.38 & 0.09 & -0.2 & 0.2 & -1.14 \\
\hline D & 8 & -1.5 & 3 & -0.82 & 0.75 & 6.4 & 0 & -1.7 \\
\hline $\mathbf{E}$ & 27 & 0.99 & 18 & 2.81 & .015 & 0.4 & 0.37 & -0.65 \\
\hline $\mathbf{F}$ & 25 & 0.72 & 9 & -0.1 & 5 & 0.9 & 2 & -1.08 \\
\hline G & 6 & 1.74 & 6 & -1.06 & 0 & -1.1 & 0 & -1.74 \\
\hline $\mathbf{H}$ & 18 & -0.17 & 8 & -0.41 & 0.06 & -0.5 & 0.13 & -1.35 \\
\hline I & 31 & -1.5 & 8 & -0.42 & 0.10 & -0.1 & 0.25 & -1.0 \\
\hline
\end{tabular}

${ }^{*}$ Liles et al. (1989). 
Table 2

Telling Task; Total Number of Cohesive Ties per T Unit and Total Number of Referential, Lexical, and Conjunctive Ties per T Unit, and $z$ Scores for Each CHI Subject

\begin{tabular}{|c|c|c|c|c|c|c|c|c|}
\hline \multirow[b]{2}{*}{ Subjects } & \multicolumn{2}{|c|}{ Total Ties Ratio } & \multicolumn{2}{|c|}{ Reference } & \multicolumn{2}{|c|}{ Lexical } & \multicolumn{2}{|c|}{ Conjunctive } \\
\hline & Number & $z$ Score & Number & $z$ Score & Number & $z$ Score & Number & $z$ Score \\
\hline \multicolumn{9}{|l|}{ Normal:* } \\
\hline$M$ & 2.51 & - & 1.62 & - & 0.30 & - & 0.60 & - \\
\hline$S D$ & 0.53 & - & 0.36 & - & 0.19 & - & 0.25 & - \\
\hline Range & $1.25-4.20$ & - & $1.00-3.00$ & - & $0.04-0.62$ & - & $0-0.92$ & - \\
\hline \multicolumn{9}{|l|}{ CHI: } \\
\hline A & 1.41 & -2.07 & 0.76 & -2.38 & 0.47 & 0.89 & 0.17 & -1.72 \\
\hline B & 2.92 & 0.77 & 1.42 & -0.55 & 0.42 & 0.63 & 1.08 & 1.92 \\
\hline C & 1.63 & -1.66 & 0.72 & 0.03 & 0.27 & -0.15 & 0.63 & 0.12 \\
\hline D & 8.11 & 10.5 & 3.62 & 2.09 & 2.62 & 0.21 & 1.81 & -1.21 \\
\hline E & 2.55 & 0.08 & 0.77 & -2.36 & 0.59 & 1.52 & 1.18 & 2.32 \\
\hline $\mathbf{F}$ & 1.84 & -1.26 & 0.92 & -1.94 & 0.64 & 1.79 & 0.28 & -1.28 \\
\hline G & 1.00 & -2.85 & 0.33 & -3.58 & 0.00 & -1.58 & 0.67 & 0.28 \\
\hline $\mathbf{H}$ & 2.61 & 0.19 & 1.56 & -0.17 & 0.22 & -0.42 & 0.83 & 0.92 \\
\hline I & 2.52 & 0.02 & 1.55 & -0.19 & 0.06 & -1.26 & 0.90 & 1.20 \\
\hline
\end{tabular}

${ }^{*}$ Liles et al. (1989).

Table 3

Generation Task; Total Number of Cohesive Ties per $T$ Unit and Total Number of Referential, Lexical, and Conjunctive Ties per T Unit, and $z$ Scores for Each CHI Subject

\begin{tabular}{|c|c|c|c|c|c|c|c|c|}
\hline \multirow[b]{2}{*}{ Subjects } & \multicolumn{2}{|c|}{ Total Ties Ratio } & \multicolumn{2}{|c|}{ Reference } & \multicolumn{2}{|c|}{ Lexical } & \multicolumn{2}{|c|}{ Conjunctive } \\
\hline & Number & z Score & Number & z Score & Number & $z$ Score & Number & $z$ Score \\
\hline \multicolumn{9}{|l|}{ Normal:* } \\
\hline$M$ & 2.86 & - & 2.08 & - & 0.19 & - & 0.59 & - \\
\hline$S D$ & 0.60 & - & 0.54 & - & 0.13 & - & 0.27 & - \\
\hline Range & $1.70-4.83$ & - & $1.30-3.67$ & - & $0-0.42$ & - & $0-1.17$ & - \\
\hline \multicolumn{9}{|l|}{ CHI: } \\
\hline A & 1.25 & -2.68 & 0.75 & -2.46 & 0.25 & 0.46 & 0.25 & -1.26 \\
\hline B & 3.00 & 0.23 & 1.50 & -1.07 & 0.50 & 2.38 & 1.00 & 1.52 \\
\hline C & 2.40 & -0.76 & 1.20 & -1.63 & 0.80 & 4.69 & 0.40 & -0.70 \\
\hline D & 4.99 & 3.55 & 1.66 & -2.00 & 2.00 & -1.43 & 1.33 & -2.55 \\
\hline $\mathbf{E}$ & 2.83 & -0.05 & 1.33 & -1.39 & 0.55 & 2.76 & 0.94 & 1.30 \\
\hline $\mathbf{F}$ & 1.78 & -1.80 & 1.00 & -2.00 & 0.22 & 0.23 & 0.56 & -0.11 \\
\hline G & 1.17 & -2.82 & 1.00 & -2.00 & 0.00 & -1.46 & 0.17 & -1.56 \\
\hline $\mathbf{H}$ & 2.25 & -1.02 & 1.38 & -1.30 & 0.25 & 0.46 & 0.63 & 0.15 \\
\hline I & 3.38 & 0.87 & 1.75 & -0.61 & 0.25 & 0.46 & 1.38 & 2.93 \\
\hline
\end{tabular}

*Liles et al. (1989).

narratives were longer in telling than in generation. The current subjects found the generation task more difficult and tended to consistently use a greater number of referential cohesive markers to help maintain linguistic organization and to structure and communicate the story.

It can be concluded that the majority of subjects (88\%) supported the finding that the CHI subjects' discourse limitations were least evident at the level of sentence formulation, regardless of the task, and most evident in the linguistic and cognitive organization of the text (Liles et al., 1989). This conclusion would lead to the suggestion that clinicians providing treatment to $\mathrm{CHI}$ clients may want to look in more depth at their clients' linguistic and cognitive organization in a variety of discourse situations. It is evident that additional, extensive analysis of the discourse of $\mathrm{CHI}$ adults is needed.

\section{REFERENCES}

Coelho, C., Liles, B. Z., \& DufFy, R. J. (1987, March). Use of narrative discourse analysis with traumatically brain injured adults.
Paper presented at the Maryland Institute for Emergency Medical Services Systems, Third National Traumatic Brain Injury Symposium, Baltimore.

Halliday, M. A. K., \& Hasan, R. (1976). Cohesion in English. London: Longman Group Limited.

Liles, B. Z., Coelho, C., Duffy, R. J., \& Zalagens, M. R. (1989). Effects of elicitation procedures on the narratives of normal and closed head-injured adults. Journal of Speech \& Hearing Disorders, 54, 356-366.

Mentis, M., \& Prutting, C. A. (1987). Cohesion in the discourse of normal and head-injured adults. Journal of Speech \& Hearing Research, 30, 88-98.

WycoFf, L. H. (1984). Narrative and procedural discourse following closed head injury. Unpublished doctoral dissertation, University of Florida.

(Manuscript received December 23, 1991.) 